\title{
Proposal And Pilot Study Of Introductory Learning Course In Personal Computers For Japanese Senior Citizens
}

Akie Yamauchi, Hitachi Management Partner, Corp., Japan

Takami Yasuda, Graduate School of Information Science Nagoya University, Japan

Shigeki Yokoi, Graduate School of Information Science Nagoya University, Japan

\begin{abstract}
We propose a new introductory course in personal computers for senior citizens who have not yet successfully learned how to operate them. In this paper, we discuss that existing IT class courses, their relevant problems, and the development of a course to solve these problems.
\end{abstract}

\section{INTRODUCTION}

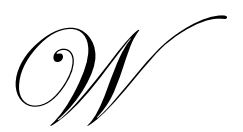

hen Japanese senior citizens first learn how to operate a personal computer, the digital divide annoys them. The operation of such devices is too complicated, and PC applications filled with technical terms are too confusing. They have difficulty inputting letters by keyboard because the character layout is unfamiliar especially if they never used a typewriter when they were younger or while working. Now, support in the form of instruments and introductory PC course are providing a path that solves the digital divide. For example, Komatsu et al. investigated senior citizens who have never used computers to determine the main factors for learning progress. They analyzed the progress of the computer literacy of senior citizens who used information supply services, and concluded that utilizing information is influenced by the operation ability of such equipment such as computers [1]. Yamamoto et al. held IT learning classes for highly motivated seniors and beginners and researched how seniors experience the Internet [2].

However, these courses are difficult for seniors who just have started to learn. Therefore a gap exists between users' skills and the courses' content some seniors cannot keep up with the basic courses. Our approach proposes a course that helps seniors "graduate" from introductory to more common courses. So, we propose a new introductory PC course for senior citizens who have not yet successfully operated computers and are learning them for the first time. First we researched existing IT learning classes and clarified the relevant problems. Next, we discuss a new course that solves these problems, and we report the results of applying it on a testee. Our research helps those who are operating a computer for the first time or who have dropped behind in their class in their IT learning classes. Moreover, the teachers of such classes can also use this method.

In this paper, we report about this course and a pilot study that observed one person. We introduce IT learning classes in Japan, in Section 2 and explain the new course in Section 3. Then, in Section 4, we describe a pilot study using this course, offer a conclusion, and discuss our future works.

\section{PROBLEMS OF COURSES IN JAPANESE IT LEARNING CLASSES}

\subsection{Senior Citizen Internet Usage}

In Japan, the retirement age is 60 . After retirement [3] people must consider how to use the remaining free time of their lives. They often want to learn something challenging [4][5][6]. Using the Internet is becoming a more popular challenge among senior citizens; Internet usage rates among people 60 or over are still much lower than 
others, but the rate increased 2.43 times between 2001 and 2004 [7][8]. One in six seniors uses the Internet. Because senior citizens want to learn how to use personal computers. IT learning classes are being held for them in Japan.

However, senior citizens sometimes feel that computers are terrible devices; for example, they may think that if they make a mistake, they will break the computer. Further difficulties in computer operation are related to weakened vision and memory problems. Since seniors hove trouble learning by themselves, they join classes. In addiction, because textbooks are filled with technical terms they cannot understand them.

Senior citizens want an environment that helps them solve the digital divide, which includes such difficulties as operating a computer, jargon-laden textbooks, and confusing manuals. IT learning classes are held all over Japan to supply such an environment.

\subsection{IT Learning Classes For Senior Citizens In Japan}

In IT learning classes, senior citizens study many things about operating the computers. According to the websites of learning classes these courses offer mouse practice, letter input with a keyboard, Internet browsing, sending/receiving e-mail, and later a variety of more advanced applications. Many IT learning classes teach computer subjects in a particular order. An IT instructor from one company said, "Mouse practice and letter input with a keyboard are basic, so learners have to study them first. They must learn these sufficiently before progressing to the next steps."

The course in the e-namo project is different from others [9]. Developed and managed by Nagoya, two universities, and an NPO, its aim is to develop a total support environment for helping senior citizens use the Internet. Since October 2005, it has held IT learning classes at sixteen local Lifelong Learning Centers for almost 3,000 senior citizens throughout the city. In the e-namo project class, one teacher instructs about ten students with teaching assistants who are a half of learners. School sessions run for four hours, and students must attend them twice. In this course, they learn the following: using a mouse, browsing, sending/receiving e-mail, and letter input with special e-namo software that only requires users to manipulate a mouse.

\subsection{Problems Faced By Seniors}

The leaning class is difficult for beginners. An e-namo questionnaire was sent to 430 persons, 173 of whom had previously joined another IT learning class. In this class, most seniors could use a mouse and manage beginner applications. This result of the e-namo questionnaire points out that the other courses are difficult for beginners. Therefore, difficulty arises when operating a personal computer to input letters by keyboard doing common applications.

\section{INTRODUCTORY LEARNING COURSE}

In this section, we explain our proposed course for solving the problem outlined in 2.3.

\subsection{Course flow}

The new course we developed is conducted in four steps, as shown in Fig. 1 and involves NPO/volunteers/ companies and the e-namo project. All courses start with mouse practice for operating a computer. 


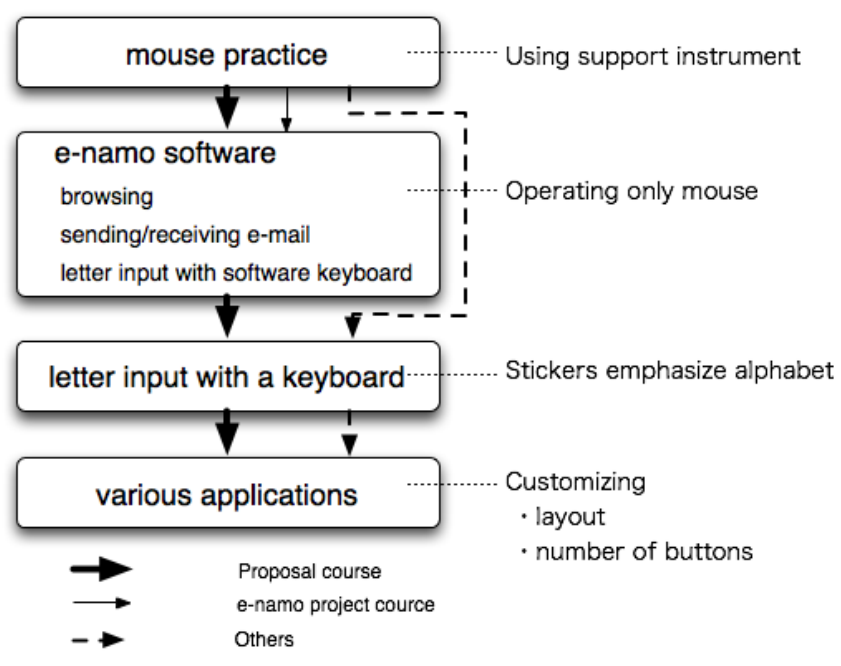

Fig. 1: Course flow

This course applies the e-namo project's learning course for beginners and an advanced course for those who have mastered the e-namo course. First, based on e-namo questionnaires, beginners felt that the courses are too difficult. One IT volunteer said, "I teach beginners how to operate a computer, and some feel that it is difficult. So I think that they should start with the e-namo software." Next, a learner who mastered e-namo course said, "I want to be more skillful." But the e-namo software is made for helping beginners. Therefore, to solve the gap between a goal of e-namo course and learners who mastered it, we added these new steps: letter input by keyboard, Internet browsing, sending/receiving e-mail, and letter input with more commonly used applications.

\subsection{Course Details}

\subsubsection{Mouse Practice}

Learners operate the computer with a mouse, which is easy to buy, provides stable performance, and is supported by common equipment. However, some learners cannot use the mouse well due to trembling hands and fingers. Therefore, a support instrument called maupii is attached to the center of the mouse, allowing learners to set their fingers above it [10] (Figs. 2 and 3). After starting the computer, they practice with the mouse using software designed as a game for learning how to click.

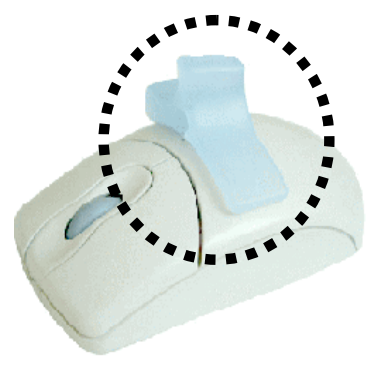

Fig. 2: Support instruments for mouse

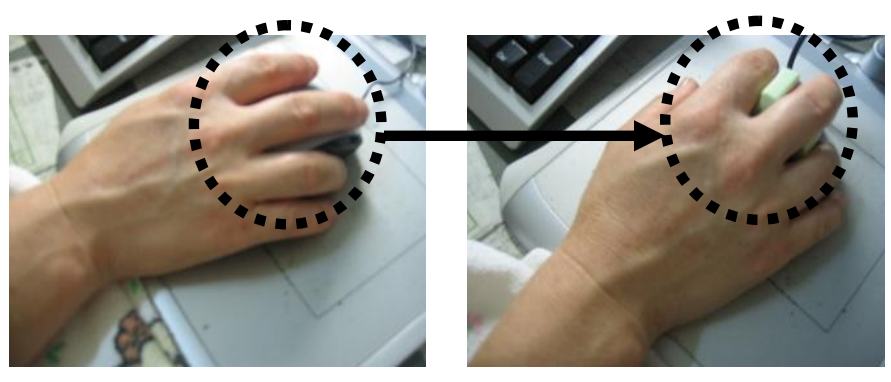

Fig. 3: Without support instrument (left), using it (right) 


\subsubsection{Letter input, browsing and sending/receiving e-mail with e-namo software}

The e-namo software, developed by the e-namo project, is an application for senior citizens and beginners that includes a software keyboard, a web browser, and a web mailer (Figs. 4, 5, and 6). In that developed by e-namo project. It was developed based on three concepts for user ease. A display design considers the cognitive characteristics of users. It also uses larger buttons, a single window, contrast with brightness of images and background, and simplified language to provide reliable contents. E-namo software has functions based on concepts for user ease. For example, the software keyboard appears when the system requests a user to input a letter; it doesn't hinder operation. The e-namo web browser has eight fewer buttons for users to monitor as well as a topic path and a link list selected by the e-namo project. Users search or browse with it. Finally, the e-namo web mailer features a mailer interface design based on a letter format to avoid confusing senior citizens.

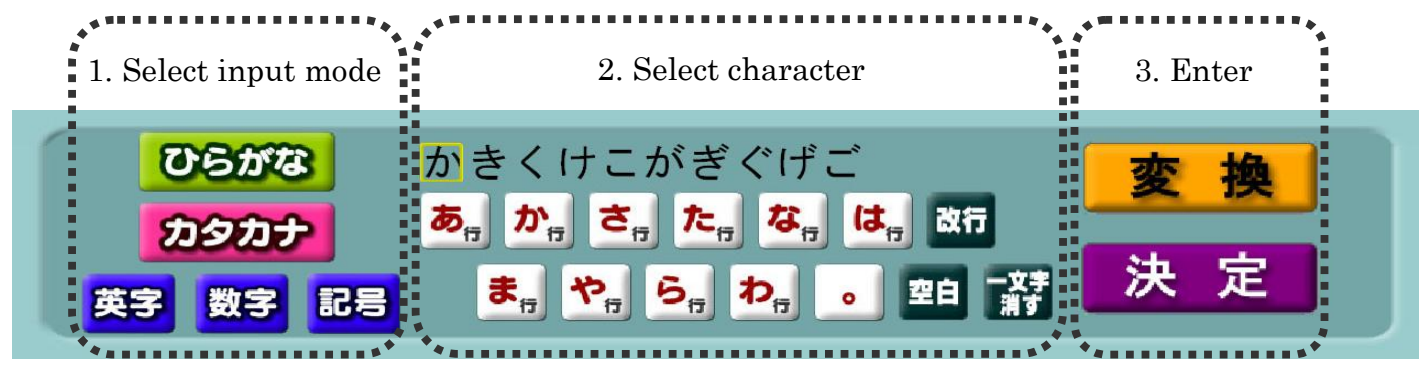

Fig. 4: E-namo software keyboard

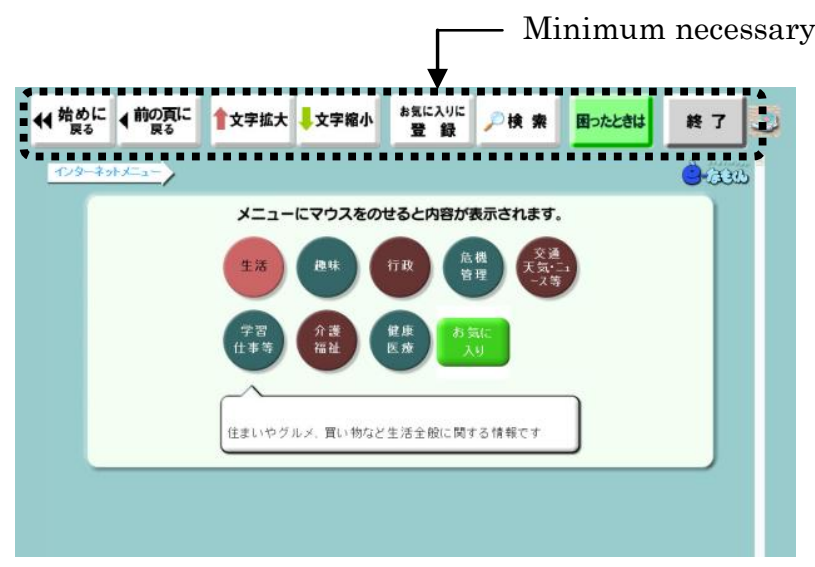

Fig. 5: E-namo web browser

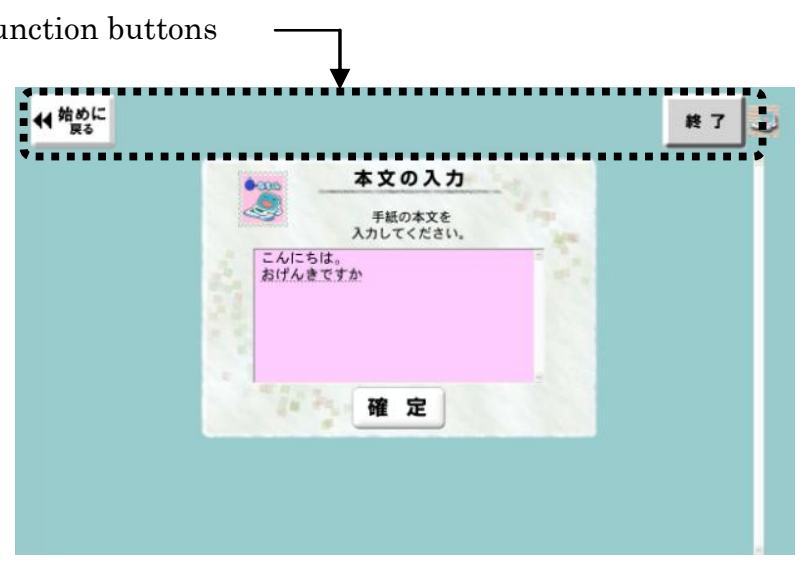

Fig. 6: E-namo web mailer

\subsubsection{Letter Input By The Keyboard}

After learners can operate the e-namo software using mouse, they practice letter input by keyboard and textbook by selecting either roman or kana input modes. These input modes are adopted in Japanese keyboard; the roman input mode (called roma-ji input mode) show hiragana by a combination of alphabet, and kana input mode show it by a kana printed on a key. If some learners don't know the roma-ji teachers use stickers that emphasize it [11] by showing the alphabet in roman letter mode to learners. High-use letters are in a large font and a noticeable color, and the low-use letters are in a small font; for example, we use a large font and red for "a", and a small font and black for "c." (Figs. 7 and Table 1.) Accordingly, senior citizens can locate the alphabet. 


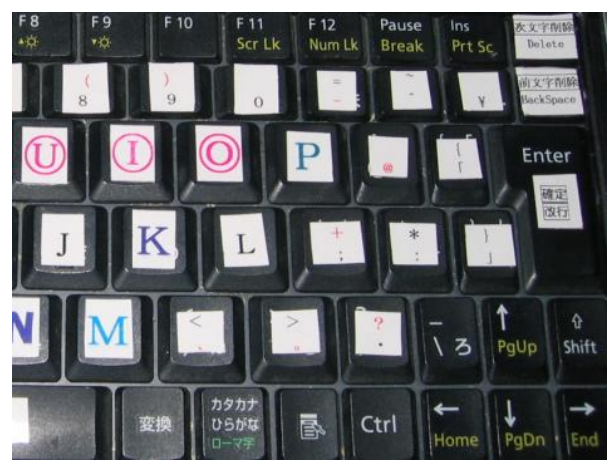

Fig.7: using stickers

Senior citizens have difficulty learning keyboard operating because the Japanese style keyboard is smaller than its English counterpart. Japan uses a Japanese Industrial Standards (JIS) keyboard that includes both kana letters and the alphabet. Our textbook explains how to input roman letters by showing Japanese equivalents since it is especially difficult to input a syllabic nasal consonant or a double consonant. It also shows Japanese syllabic order, greeting messages, and basic words.

Table 1: Emphasis of sticker style

\begin{tabular}{|c|c|c|}
\hline Character & Letter Style & Use in Roman Letter Mode \\
\hline $\mathrm{A}, \mathrm{E}, \mathrm{I}, \mathrm{O}, \mathrm{U}$ & magenta, circled & vowel \\
\hline $\mathrm{K}, \mathrm{S}, \mathrm{T}$ & blue, ming-cho type & consonant \\
\hline $\mathrm{N}$ & blue, gothic & consonant or syllabic \\
\hline $\mathrm{H}, \mathrm{M}, \mathrm{R}, \mathrm{W}$ & cyan, ming-cho type & consonant \\
\hline Y & cyan, gothic & $\begin{array}{l}\text { 1. consonant } \\
\text { 2. contracted sound } \\
\text { (combine with a consonant and a vowel) }\end{array}$ \\
\hline $\mathrm{B}, \mathrm{D}, \mathrm{G}, \mathrm{Z}$ & green, ming-cho type & voiced consonant \\
\hline $\mathrm{P}$ & blue green, ming-cho type & voiced consonant ("p" sounds) \\
\hline $\mathrm{C}, \mathrm{F}, \mathrm{V}, \mathrm{L}, \mathrm{Q}$ & black, ming-cho type, small font & low use in roman letter mode \\
\hline $\mathrm{X}$ & black, bold, ming-cho type, small font & input small characters \\
\hline numbers & black, More smaller font, ming-cho type & \\
\hline
\end{tabular}

\subsubsection{Letter Input, Browsing, And Sending/Receiving Mail With More Commonly Used Applications}

Finally of course, learners who join other learning classes typically study browsing, sending/receiving e-mail, and letter input with more commonly used applications such as Microsoft Internet Explorer (IE), Outlook Express (OE), and WordPad. But these applications have many functions, so senior citizens feel for them in the display. Therefore, the number of functions taught with such applications equals the number of functions used by the e-namo software. IE and OE show many buttons in the initial condition. Senior citizens often get confused and say, "what are these buttons for?" Therefore, the number of functions taught with such applications equals the number of functions used by the e-namo software. IE shows five buttons: back, forward, homepage, favorite, and search (Fig. 8). OE shows a send button, to field, cc field, subject field, and body of mail in the compose window, and in the main window, three parts: function buttons, mail list, and message. We selected WordPad for letter input, because it has a function for font attribute; the memo pad of Windows is too small and Microsoft Word has a lot of buttons and functions. 


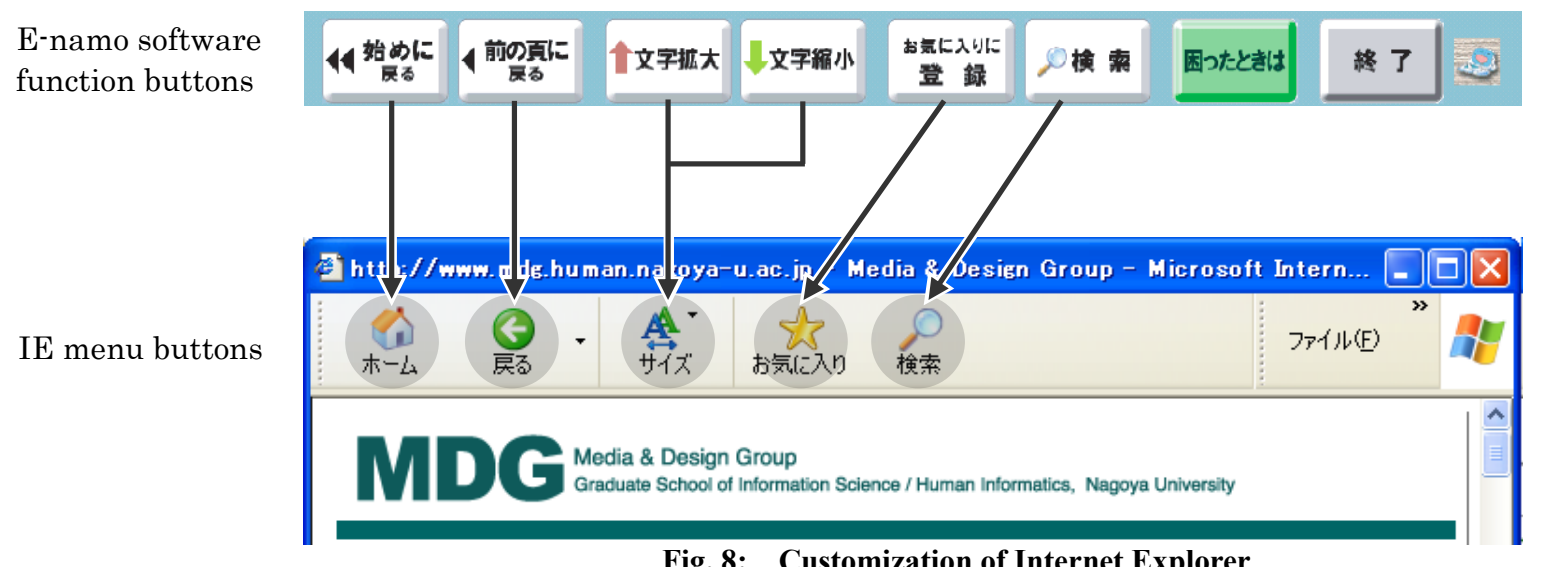

Fig. 8: Customization of Internet Explorer

\section{PILOT STUDY}

The pilot study determined at which point learners felt perplexed in this course. We observed a fifty-three-year-old woman who had never operated a computer or attended IT learning classes. She learned how to operate a computer from a teacher in a class of two hours held ten times once a week.

As a result of this experiment, the test user did not experience difficulty graduating from the e-namo software to IE and OE. But she did have difficulty fixing her eyes on the display. At the conclusion of the experiment, her work speed became slower.

We considered about these results. Since the test user did not have difficulty moving the difference is small between the e-namo software's function and those of IE and OE. This suggests that users can find the appropriate buttons; if they change applications, they must have remembered the functions and layout. However, we have to find another way to provide a customized environment. Before this experiment, the teacher customized the environment for the test user. When this course is used in a real class, it will be difficult for senior citizens to set customized environments. We can set the same environment with Windows registry, but the system might suffer. So, teachers and skillful persons should customize. During the experiment, to become slower test user's work speed, perhaps her skill and eagerness decreased because she was facing a situation where she didn't want to find anything. The solution is to arrange interesting topics for learners and guide them to appropriate website.

\section{CONCLUSION}

In this paper, we proposed an IT learning course for Japanese senior citizens who have never used a PC and who have dropped existing IT learning classes and feared inputting letters by keyboard and operating applications. We planned a course to solve their fears that also addressed operation difficulty and experimented with one test user, who learned how to operate the applications and input the letter with which seniors experience difficulty. This suggests that the course might acts as a go-between for those who have never learned about computers and existing commonly courses.

Finally, we discussed the position of this research. Senior citizens often consider using PCs, and in the future, their use will increase because many citizens often use it during work. However, we believe that this course can benefit senior citizens who are waiting for a chance to learn computers. 


\section{AUTHOR INFORMATION}

Akie Yamauchi is a planner of Hitachi Management Partner, Corp. Her focus is elementary learning and education in relation to information devices and software interface. She received her masters degree in Information Science from Nagoya University at Japan in 2005. She was a withdrawal from the Doctoral Program of Nagoya University with the completion of course requirements in 2008.

Takami Yasuda is a professor in the Graduate School of Information Science at Nagoya University. His research interests social and educational applications of information technologies in the Net. Yasuda received his Ph.D. in Information Engineering from Nagoya University in 1989. He won the Director-General of the Science and Technology Agency prize in 1995. He also received Sakai Special Researcher Award and Activity Contribution Award from Information Processing Society of Japan in 1998 and 2006, respectively. He got Best Paper Awards from Japanese Society for Medical and Biological Engineering and Japanese Society for Information and Systems in Education in 1987 and 2001, respectively.

\section{Shigeki Yokoi}

-Research Career

He graduated from the doctor course of graduate course of Nagoya University. He joined in Nagoya University as a research assistant in 1977. He became an associate professor in Mie University in 1978. He became an associate professor in Engineering Department in Nagoya University in 1982. He became a professor in School of Informatics and Sciences in Nagoya University in 1998. He has been a professor in the Graduate School of Information Science since 2003. He is a Dean of School of Informatics and Sciences in Nagoya University currently.

-Current Research

Research on the relationship between technology and real society within our electronic society

-Keywords

Electronic society system/ information security/ technologies on the Web and CG

-Content of research

He is interested in researching the processes inherent in the creation of new our society, making use of Internet and image media. To this end, we must understand technological innovation precisely, and investigate in detail its applications to actual society.

\section{REFERENCES}

1. K.Komatsu, et al. (2002), "A study on guidance of computer operation considering the elderly", Journal of Socio-Information Studies, No.6, pp.1-12, 2002

2. K.Yamamoto, et al, (2002), "A Trial of The Internet Lecture Class for The Senior Citizens", Gifu City Women's college (ISSN:09163174), pp.15-23

3. Hakuhodo's Elder Business Development Division (2005), "HOPE Report XIX"

4. Senior Summer College: http://www.sscollege.jp/

5. Mitaka NETWORK University: http://www.mitaka-univ.org/

6. The Cabinet Office, Annual Report on the Aging Society, 2004

7. Ministry of Internal Affaires \& Communications, Communications Usage Trend Survey H.13, 2002

8. Ministry of Internal Affaires \& Communications, Communications Usage Trend Survey H.16, 2005

9. e-namo project: http://www.u-net.city.nagoya.jp/e namo/

10. AOI (a company made Maupii): http://www13.ocn.ne.jp/ maupii/

11. ISO3602:1989 Documentation - Romanization of Japanese (kana script) 
NOTES 